\title{
Can thyroid dysfunction in mothers influence neonatal thyroid profile?
}

\author{
Menon $\mathbf{M}^{1}$, Sreejyothi $\mathrm{G}^{2}$, Raveendranath. $\mathrm{K}^{3}$ \\ ${ }^{1}$ Dr. Maya Menon, Associate Professor, ${ }^{2}$ Dr. Sreejyothi. G, Assistant Professor, ${ }^{3}$ Dr. Raveendranath. K, Professor and \\ HOD, Department of Paediatrics, SUT Academy of Medical Sciences, TVM, Kerala, India.
}

Address for Correspondence: Dr. Maya Menon, Email: dr.mayamenon94@gmail.com

\begin{abstract}
Thyroid hormones play a critical role in normal CNS maturation. Fetus is entirely dependent on maternal thyroid hormone before the onset of endogenous thyroid hormone production. Maternal hypothyroidism alone during early gestation can lead to mild but significant cognitive impairment of the offspring. Infants of mothers with thyroid problem are more likely to have elevated TSH during newborn screening. Aim of the Study: The study was done to know whether maternal thyroid dysfunction can influence neonatal thyroid profile. Materials and Methods: This was a prospective cohort study in which 171 neonates who satisfied the inclusion criteria were serially enrolled during the study period. Of the 171 neonates enrolled, 70 neonates were born to mothers with thyroid dysfunction and 101 neonates were born to normal mothers. TSH estimation was done in all enrolled neonates at $72 \mathrm{hrs}$ and result interpreted using AAP guidelines. Results: Out of 171 neonates, 155 babies (91\%) had a TSH value of $<10 \mathrm{mIU} / \mathrm{L}, 14(8 \%)$ had TSH between 10 and $40 \mathrm{mIU} / \mathrm{L}$ and 2 babies $(1 \%)$ had $\mathrm{TSH}>40 \mathrm{mIU} / \mathrm{L}$. All the neonates who had TSH $>40 \mathrm{mIU} / \mathrm{L}$ were born to mothers with thyroid dysfunction. Neonates who had TSH $>40 \mathrm{mIU} / \mathrm{L}$ were all females where as there was a male predominance in the group who had TSH between 10 and $40 \mathrm{mIU} / \mathrm{L}$. Conclusion: It may be concluded that maternal thyroid hormones play a crucial role in the thyroid function status of newborns and their early neurodevelopment.
\end{abstract}

Keywords: Congenital Hypothyroidism, Thyroid Hormones, Thyroid Stimulating Hormone, Maternal Thyroxine, Newborn screening

\section{Introduction}

Maternal thyroxine is critical for normal CNS maturation in the fetus [1]. The thyroxine concentration is low in the fetus during the first half of pregnancy, before the onset of endogenous thyroid hormone production in the fetus [2]. During this time the fetus is entirely dependent on maternal thyroid hormone; its supply to the fetus is controlled by placenta and thyroid status of the mother. Transplacental thyroid hormones supply to fetus is modulated by several factors including the following proteins: plasma membrane transporters which regulate the passage of thyroid hormones in and out of cells, iodothyronine deiodinase which metabolize thyroid hormones and proteins within trophoblast cells which bind thyroid hormones [3]. In pathological situations of either maternal or fetal thyroid hormone deficiency during pregnancy, the placenta seems to lack the full compensatory

Manuscript received: $17^{\text {th }}$ May 2016

Reviewed: $28^{\text {th }}$ May 2016

Author Corrected; $14^{\text {th }}$ June 2016

Accepted for Publication: $25^{\text {th }}$ June 2016 mechanisms necessary to optimize maternal-fetal transfer of thyroid hormones. Inadequate passage of thyroid hormones, can lead to suboptimal fetal thyroid hormone levels which might contribute to the neurodevelopmental delay associated with such conditions. Thus maintaining normal maternal thyroid hormone status is likely to be the primary factor in ensuring adequate transplacental thyroid hormone passage and appropriate iodide supply to the fetus.

Thyroid embryogenesis occurs during the first trimester. By 10-12 weeks, the fetal thyroid gland demonstrates the ability to concentrate iodide and synthesize iodothyronines. TRH, somatostatin and TSH are also detectable by this age.

However the activity of Hypothalamo Pituitary axis is low and circulating TSH and T4 levels are minimum until approximately 18-20 weeks. After 20 weeks, there is a progressive increase in TSH and Free T4 level [4]. 
The normal full term neonate shows a marked and a rapid increase in serum TSH within 30 minutes of birth (60-80 $\mathrm{mIU} / \mathrm{L})$. This decreases rapidly to about 20 $\mathrm{mIU} / \mathrm{L}$ at 24 hours and then more slowly to 6-10 $\mathrm{mIU} /$ Lat one week. The initial surge in TSH stimulates thyroidal T4 secretion so that serum T4 and T3 concentration rise to peak at 24-36 hours. They gradually fall in the first few weeks of life levelling off to just slightly above the adult level [2].

Despite the critical importance of thyroid hormone on multiple organ systems especially the brain most infant with congenital hypothyroidism appear normal at birth [2]. So every infant should be tested before discharge from the nursery optimally by 48 hours to 4 days of age. As noted above, specimen collected in first 24-48 hours of life may lead to false TSH elevation. But screening before discharge is preferable to missing the diagnosis of hypothyroidism. According to AAP guidelines there are two strategies for the detection of congenital hypothyroidism -A primary TSH/back up T4 method and a primary T4/ backup TSH method. Any infant with low T4 concentration and TSH $>40 \mathrm{mIU} / \mathrm{L}$ is considered to have congenital hypothyroidism. For cases in which screening TSH concentration is only slightly elevated but $<40 \mathrm{mIU} / \mathrm{L}$, a repeat test is to be done. As $10 \%$ of infants with congenital hypothyroidism have TSH value between 20 and $40 \mathrm{mIU} / \mathrm{L}$ it is important to use age appropriate normal value. The reference range for TSH for most common time of TSH revaluation (between 2 and 6 weeks of age) is 1.7 to $9.1 \mathrm{mIU} / \mathrm{L}$. Congenital hypothyroidism can cause mental retardation unless thyroid therapy is initiated within two weeks of birth. Hence treatment with replacement levothyroxine should be initiated as soon as the confirmatory tests have been drawn and before the results of confirmatory tests are available.

Maternal hypothyroidism alone during early gestation can lead to mild but significant cognitive impairment of the off spring $[5,6]$ and treatment of maternal hypothyroidism has been subject of several recent reviews. [7, 8]. Infants of mothers with thyroid problems are more likely to have elevated TSH during newborn screening. These babies should be followed up for thyroid dysfunction in the first few months of postnatal life. Among half of newborns with abnormal screening values will have transient hypothyroidism [9] - one of the causes for this being maternal thyroid receptor binding antibodies [2,9]. Other causes of transient hypothyroidism are intrauterine exposure to maternal antithyroid drugs, dual oxidase deficiency
(DUOX2), mutations in TSH-R, endemic iodinase deficiency, prenatal or postnatal exposure to excess iodide (povidone iodine/iodinated contrast material).

Transplacental passage of potent maternal TRBAbs (incidence 1 in 80,000) is a much less common cause of transient hypothyroidism [2, 9] but should be suspected if there is a maternal history of autoimmune thyroid disease or if there is a history of previously affected sibling. The half life of IgG in neonate is approximately 3 to 4 weeks and TRBAbs usually disappear from serum of affected infants by 3 to 6 months of age depending on antibody loads.

\section{Aim of the Study}

The study was done to know whether maternal thyroid dysfunction can influence neonatal thyroid profile.

\section{Materials and Methods}

This was a prospective cohort study in which 171 neonates who satisfied the inclusion criteria were serially enrolled during the study period. Of the 171 neonates enrolled, 70 neonates were born to mothers with thyroid dysfunction and 101 neonates were born to mothers with normal thyroid function. The study was carried out at the delivery room, postnatal ward and NICU of SUT Academy of Medical Sciences, Trivandrum during the 12 months interval from February 2015 to January 2016.

\section{Inclusion criteria}

1. Study population consists of Term AGA babies born during the study period.

2. Apgar score of over 7 at 1' and 10 at 5'

3. Absence of significant illness or major congenital malformation

\section{Exclusion criteria}

1. Preterm $<37$ week

2. Birth wt $<2499 \mathrm{~g}$ and $>4000 \mathrm{~g}$

3. Mother with GDM/ hypertension or on other drugs

4. Apgar Score $<7$ at 1 ,

Institutional ethical committee approval and informed consent from parents were taken and neonates who satisfied the inclusion criteria were enrolled in the study. Detailed history using a proforma (prenatal history, maternal complications and medications, type of delivery) and physical examination (Birth weight, sex, apgar score, general examination and gestational 
age by NBS) where done. Maternal TSH was done during the first antenatal visit and neonatal thyroid profile was done at $72 \mathrm{hrs}$ in all the babies. $3 \mathrm{ml}$ of venous blood was taken at $72 \mathrm{hrs}$ from enrolled babies for estimating TSH and TSH estimation was done by enhanced chemiluminensce assay. The AAP guidelines were used to interpret the TSH values in the neonates [2].

\section{Results}

171 neonates who satisfied the inclusion criteria were serially enrolled in our study.

Fig(1): shows out of the171 neonates enrolled, 70 neonates were born to mothers with thyroid dysfunction and 101 neonates were born to mothers with normal thyroid function.

Fig (2) : shows distribution of neonates based on TSH values. Out of 171 babies, 155 neonates (91\%) had a TSH value of $/<10 \mathrm{mIU} / \mathrm{L}, 14$ (8\%) had TSH between $10 \mathrm{mIU} / \mathrm{L}$ and 2 neonates $(1 \%)$ had TSH $>40 \mathrm{mIU} / \mathrm{L}$.

Table (1) and Table(2) shows distribution of neonatal TSH based on maternal thyroid status. All the neonates who had $\mathrm{TSH}>40 \mathrm{mIU} / \mathrm{L}$ were born to mothers with thyroid dysfunction

Table (3): shows distribution of neonatal TSH based on sex . Neonates who had TSH $>40 \mathrm{mIU} / \mathrm{L}$ were all females where as there was a male predominance in the group who had TSH between $10 \mathrm{mIU} / \mathrm{L}$ and $40 \mathrm{mIU} / \mathrm{L}$.

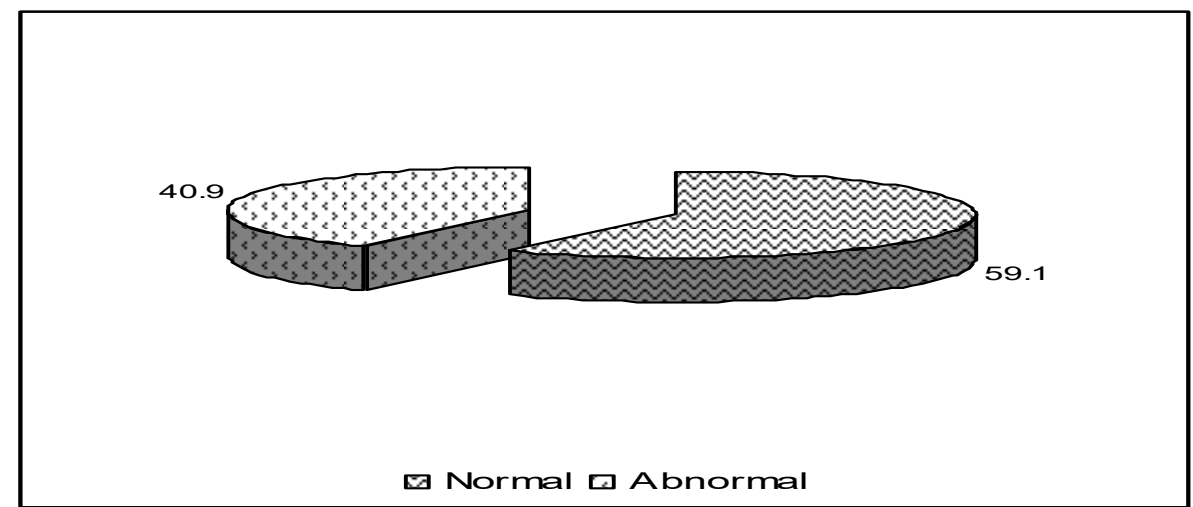

Fig.-1: Percentage distribution of the sample according to maternal thyroid status

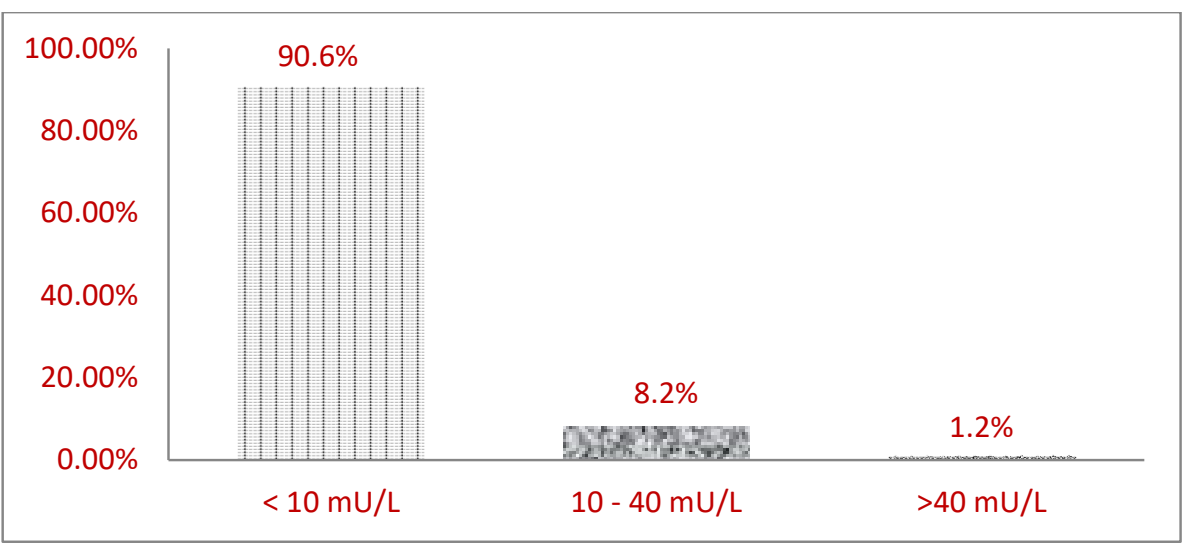

Fig. 2 Distribution of neonates based on TSH Levels. 
Table- 1: Distribution of TSH levels in Neonates born to mothers with normal Thyroid status.

\begin{tabular}{|c|c|c|}
\hline Neonatal TSH & No: of babies & Percentage \\
\hline$<10 \mathrm{mU} / \mathrm{L}$ & 95 & 94.1 \\
\hline $10 \mathrm{mU} / \mathrm{L}-40 \mathrm{mU} / \mathrm{L}$ & 6 & 5.9 \\
\hline$>40 \mathrm{mU} / \mathrm{L}$ & 0 & 0.0 \\
\hline Total & $\mathbf{1 0 1}$ & $\mathbf{1 0 0}$ \\
\hline
\end{tabular}

Table- 2: Distribution of TSH levels in Neonates born to mothers with abnormal Thyroid status.

\begin{tabular}{|c|c|c|}
\hline Neonatal TSH & No: of babies & Percentage \\
\hline$<\mathbf{1 0} \mathbf{~ m U} / \mathbf{L}$ & $\mathbf{6 0}$ & $\mathbf{8 5 . 7}$ \\
\hline $10 \mathrm{mU} / \mathrm{L}-40 \mathrm{mU} / \mathrm{L}$ & $\mathbf{8}$ & $\mathbf{1 1 . 4}$ \\
\hline$>40 \mathrm{mU} / \mathrm{L}$ & $\mathbf{2}$ & $\mathbf{2 . 9}$ \\
\hline Total & $\mathbf{7 1}$ & $\mathbf{1 0 0}$ \\
\hline
\end{tabular}

Table- 3: Distribution of neonatal TSH based on sex.

\begin{tabular}{|c|c|c|c|c|c|c|}
\hline \multirow{2}{*}{ Neonatal TSH } & \multicolumn{2}{|c|}{ Male } & \multicolumn{2}{c|}{ Female } & \multirow{2}{*}{ Z } & \multirow{2}{*}{ P } \\
\cline { 2 - 6 } & Count & Percent & Count & Percent & & 0 \\
\hline$<10 \mathrm{mU} / \mathrm{L}$ & 98 & 63.2 & 57 & 36.8 & $3.339 * *$ & 0 \\
\hline $10 \mathrm{mU} / \mathrm{L}-40 \mathrm{mU} / \mathrm{L}$ & 10 & 71.4 & 4 & 28.6 & $5.434^{* *}$ & 0 \\
\hline$>40 \mathrm{mU} / \mathrm{L}$ & 0 & 0.0 & 2 & 100.0 & $13.077^{* *}$ & 0 \\
\hline
\end{tabular}

**: - Significant at 0.01 level

\section{Discussion}

Maternal hypothyroidism alone during early gestation can lead to mild but significant cognitive impairment of the offspring. This is because foetus is entirely dependent on the maternal thyroxine before the onset of endogenous thyroid hormone production. Infants of mothers with thyroid problems are more likely to have elevated TSH during newborne screening.

In this study we investigated the thyroid status of the neonates at 72 hours of age who were delivered in our hospital during the study period. We were able to enroll 171 mothers and their newborns after satisfying the inclusion criteria. $40 \%$ of the mothers were found to have thyroid dysfunction and were on thyroxine replacement therapy. This increased incidence of hypothyroidism may be attributed to the fact that thyroid disorder is one of the commonest endocrine disorders in women and hence constitutes the commonest endocrine disorder complicating pregnancy.
Also hypothyroidism both overt and subclinical is common in reproductive age and during pregnancy with frequency ranging from 0.35 to $2.5 \%$ [10]. The high prevalence of hypothyroidism may also be contributed by the dietary deficiency of iodine and geographic variation [11].

In our study, we found that $91 \%$ of newborns had a TSH value $<10 \mathrm{mU} / \mathrm{L}, 8 \%$ had a TSH value between $10 \mathrm{mIU} / \mathrm{L}$ and $40 \mathrm{mIU} / \mathrm{L}$ and $1 \%$ had a $\mathrm{TSH}$ value $>40 \mathrm{mIU} / \mathrm{L}$. Among the 16 newborns with elevated TSH, 2 newborns with TSH $>40 \mathrm{mIU} / \mathrm{L}$ and 8 out of 14 newborns with TSH between 10 and $40 \mathrm{mIU} / \mathrm{L}$, were born to mothers with thyroid dysfunction.

This agrees with the study by Richard et al [12] which showed that a parental history of hypothyroidism was associated with both transient as well as congenital hypothyroidism, In our study the incidence of neonates 
with $\mathrm{TSH}>40 \mathrm{mU} / \mathrm{L}$ is more than in general population. This high prevalence of congenital hypothyroidism noticed in our study agrees with the study by Mayinka et al [11] which showed variation of incidence of congenital hypothyroidism according to geographical location. They also noticed that the incidence of hypothyroidism is highest in Asian population.

Among the neonates with elevated TSH, it was noted that female babies predominated the group with $\mathrm{TSH}$ $>40 \mathrm{mU} / \mathrm{L}$ and male babies predominated the group with $\mathrm{TSH}$ between $10 \mathrm{mU} / \mathrm{L}$ and $40 \mathrm{mU} / \mathrm{L}$.

This agrees with the study by Park et al [13] who has reported a female to male ratio of 2:1 for true congenital hypothyroidism and 1:1 or lower in case of transient hypothyroidism. Medda et al [14] also reported an elevated female to male ratio only for congenital hypothyroidism not for transient hypothyroidism. Richard et al cites female to male ratio as a distingushing factor between congenital and transient hypothyroidism.

Nearly all screening programmes report 2:1 female to male ratio in congenital hypothyroidism [15].

\section{Conclusion}

Thyroid hormones play a critical role in normal CNS maturation. Newborns with significantly elevated TSH were born to mothers with thyroid dysfunction.

Thus it can be concluded that maternal thyroid hormones play a crucial role in the thyroid function status of newborns and their early neurodevelopment.

Congenital hypothyroidism is one of the preventable causes of mental retardation and hence routine newborn screening should be initiated for the early identification and treatment before symptoms appear.

\section{Acknowledgment}

1. Dr. Sulekha. B, Professor and HOD, Department of Biochemistry.

2. Dr. Radhamony. L, Professor and HOD, Department of Obstretrics and Gynaecology.

3. Dr. Oommen P. Mathew MSc, PG D (Com. Sc), PGD (Bio Stat), PhD (Demography) Research Investigator, Population Research Centre.
Funding: Nil, Conflict of interest: Nil

Permission from IRB: Yes

\section{References}

1. Tricia Lacy Gomella, M Douglas Cunningham, Fabien G Eyal Thyroid Disorders In Neonatology $7^{\text {th }}$ edn McGraw Hill Education (India) private Ltd 2014 chapter140 p908.

2. SR Rose, RS Brown Update of newborn screening and therapy for congenital hypothyroidism. Pediatrics. June 2006,117(6): 2290-2303. 10.1542/peds.2006-0915.

3. Chan SY ${ }^{1}$, Vasilopoulou E, Kilby MD The role of the placenta in thyroid hormone delivery to the fetus. Nat Clin Pract Endocrinol Metab. 2009 Jan;5(1):45-54. doi: 10.1038/ncpendmet1026.

4. Martin.R, Cloherty JP. Neonatal Hyberbilirubinemia. In cloherty J.P, Eichenwald E .C, Stark A.R. Manual of Neonatal Care.6 edn, Philadelphia: Lippincott Williams and Wilkins, 2008.chapter 18p210-211.

5. Radetti G, Zavallone A, Gentili L, Beck-Peccoz P, Bona G. Foetal and neonatal thyroid disorder. Minerva Pediatr.2002;54(5) :383- 40 .

6. Glinoer D. Potential consequences of maternal hypothyroidism on the offspring: evidence and implications. Horm Res.2001;55 :109- 114

7. Alexander EK, Marqusee E, Lawrence Dussault JH, Jarolim P, Fischer GA, Larsen PR. Timing and magnitude of increases in levothyroxine requirements during pregnancy in women with hypothyroidism. N Engl J Med. 2004;351:241-249.

8. Escobar GM, Obregon MJ, del Rey FE. Maternal thyroid hormones early in pregnancy and fetal brain development. Best Pract Res Clin Endocrinol Metab.2004;18 :225- 248 .

9. Transient congenital hypothyroidism in Turkey. An analysis in frequency and natural course $\mathrm{J}$ clin Res Pediatr Endocrinol 2016 : 8 (2); 170-179 doi:10. 4274/jrcpe. 2.

10. Basinet $\mathrm{P}$, Aggrawal N, Suri V, Dutta P, Mukhopadhyay $\mathrm{K}$ Comparison of maternal and perinatal outcome in pregnant women with hypothyroidism diagnosed before conception with hypothyroidism diagnosed during pregnancy Journal of 
Universal College of Medical Sciences (2014)Vol 02 No.02 Issue 06.

11. Maynika V Rastogi, ${ }^{1}$ Stephen $\mathrm{H} \mathrm{La} \quad$ Franchi Orphanet Congenital hypothyroidism Journal of Rare Diseases 20105:17DOI :10 . 1186/ 1750 - 1172 - 5-17.

12. Richard S. Olney, Scott D. Grosse, Robert F. Vogt, Jr Prevalence of Congenital Hypothyroidism-Current Trends and Future Directions: Workshop Summary. Pediatrics May 2010, VOLUME 125 / ISSUE Supplement 2.
13. Parks JS, Lin M, Grosse SD, et al. The impact of transient hypothyroidism on the increasing rate of congenital hypothyroidism in the United States. Pediatrics. 2010; 125(2 suppl): S54-S63.

14. Medda E, Olivieri A Deladoëy J, Stazi MA, et al. Risk factors for congenital hypothyroidism: results of a population case-control study (1997-2003). Eur J Endocrinol. 2005; 153(6):765.

15. LaFranchi SH, Murphey WH, Foley TP, Larsen PR, Buist NR: Neonatal hypothyroidism detected by the Northwest Regional Screening Program. Pediatrics. 1979, 63 (2): 180-191.PubMedGoogle Scholar.

\section{How to cite this article?}

Menon M, Sreejyothi G, Raveendranath. K. Can thyroid dysfunction in mothers influence neonatal thyroid profile?. Int J PediatrRes.2016;3(7):503-508.doi:10.17511/ijpr.2016.i07.07. 